\title{
O CONCEITO DE LUCRO ECONÔMICO NO ÂMBITO DA CONTABILIDADE APLICADA
}

\author{
ALESSANDRA HIRANO FUJI \\ Mestre em Controladoria e Contabilidade pela FEA-USP - SP \\ E-mail: alessandra.hirano@bcb.gov.br
}

\section{RESUMO}

O estudo da Ciência Contábil e as definições de elementos financeiros, notadamente o lucro, são de grande relevância não somente para os estudiosos do meio acadêmico, mas também para aqueles que atuam no mercado financeiro e trabalham com as questões práticas da Contabilidade. O lucro contábil, que constitui basicamente o confronto entre receita realizada e custo consumido, é respaldado pelo conservadorismo, convenção da objetividade e Princípios Contábeis Geralmente Aceitos. O lucro econômico, que é o incremento do valor presente do patrimônio líquido, envolve aspectos subjetivos, mas é superior ao lucro contábil, mormente no processo decisório dos usuários internos e externos. A questão de pesquisa é se o conceito de lucro econômico encontra-se realmente difundido entre os profissionais da área contábil. O objetivo do trabalho é enfatizar a importância do conceito de lucro econômico e verificar qual o grau de assimilação, utilização e divulgação do conceito no âmbito da Contabilidade Aplicada. O trabalho, baseado em revisão da literatura e estudo exploratório mostra que o conceito de lucro econômico não é plenamente conhecido e utilizado pelos usuários da contabilidade.

Palavras-chave: Lucro Econômico, Contabilidade Aplicada, Processo Decisório.

\section{ABSTRACT}

The study of accounting theory and the definitions of financial elements, especially profit, is highly relevant not only for academics, but also for those directly involved in practical activities related to applied accounting. Accounting profit is the confrontation between revenue and cost and is based on conservatism, objectivity and Generally Accepted Accounting Principles. Economic profit is the increase in the equity's present value and involves subjective aspects, but it is better than accounting profit, mainly in the context of internal and external users' decisionmaking process. The research question is whether the concept of economic profit is really widespread among accounting professionals. This study aims to emphasize the importance of economic profit concept and to verify how this concept is assimilated, used and disclosed in the context of applied accounting. Based on a literature review and an exploratory study, this research shows that the concept of economic profit is not fully known and used by accounting users.

Keywords: Economic Profit, Applied Accounting, Decision-Making Process. 


\section{INTRODUÇÃO}

A estrutura contábil tradicional encontra-se respaldada, fundamentalmente, pela convenção da Objetividade e pelos Princípios Contábeis Geralmente Aceitos.

O lucro, tratado tanto pela Ciência Contábil quanto pela Ciência Econômica, constitui um importante referencial para o processo decisório dos agentes econômicos e um indicador de sucesso das empresas.

O lucro contábil, apurado nos moldes da estrutura contábil tradicional, visa, basicamente, ao usuário externo, não constituindo uma ferramenta rica e adequada para a tomada de decisões econômicas dos usuários das informações contábeis. O lucro econômico, cuja essência reside no incremento do valor presente do patrimônio líquido, é o conceito que realmente atende às necessidades e aos interesses dos agentes econômicos, principalmente no que tange à predição de eventos e tendências futuras.

O objetivo do presente trabalho é enfatizar a importância do conceito de lucro econômico e verificar, através de uma pesquisa junto a profissionais da área contábil atuantes no mercado, qual o grau de assimilação, utilização e divulgação do conceito no âmbito da Contabilidade Aplicada.

A questão de pesquisa é se o conceito de lucro econômico se encontra plenamente difundido e utilizado entre os profissionais da área contábil ou se as práticas contábeis continuam enraizadas pela convenção da Objetividade e pelo lucro contábil tradicionalmente apurado.

Quanto à metodologia, o trabalho possui caráter teórico-empírico, fundamentando-se em revisão da literatura e um estudo exploratório, mediante pesquisa realizada junto a profissionais da área contábil. $A$ amostra é formada por profissionais que atuam diretamente no mercado financeiro, especificamente na área de auditoria e possuem largo convívio e experiência com as questões práticas da Contabilidade. O instrumento utilizado para a coleta de dados foi o questionário, formado por cinco questões elaboradas com o intuito de averiguar o grau de assimilação, utilização e divulgação do conceito de lucro econômico. A pesquisa foi realizada durante o mês de julho de 2002, sendo que o questionário foi encaminhado, através de e-mail, a 247 pessoas, com resposta de 49, o que corresponde a $19,83 \%$.

\section{CARACTERIZAÇÃO DO PROBLEMA}

A Contabilidade, sob a égide da convenção da objetividade e do conservadorismo, com fundamento nos Princípios Contábeis Geralmente Aceitos, fornece informações voltadas, basicamente, ao usuário externo.

Segundo a Teoria Positiva da Contabilidade, as avaliações subjetivas e o conceito de valor são desnecessários, sendo que o lucro contábil tradicional é adequado, considerando-se as hipóteses do mercado eficiente e a utilização do CAPM (Capital Asset Pricing Model).

O lucro contábil é, basicamente, o resíduo do confronto entre receita realizada e custo incorrido, apurado em consonância com a convenção da Objetividade e Princípios Contábeis Geralmente Aceitos e prioriza o usuário externo das demonstrações contábeis. No caso brasileiro, há ênfase para a apuração do lucro contábil que atenda às exigências do Fisco.

O lucro econômico é, essencialmente, apurado pelo incremento no valor presente do patrimônio líquido, envolvendo aspectos ligados à subjetividade. Trata-se de um conceito mais amplo, rico e adequado do que o lucro contábil, principalmente no tocante ao processo decisório, sendo que se volta tanto ao usuário externo como o interno.

A questão de pesquisa, que reflete a problemática do tema, é a seguinte: o lucro econômico encontra-se plenamente difundido pelos profissionais da área contábil atuantes no mercado, ou seja, no âmbito da Contabilidade Aplicada?

\section{O OBJETIVO DA CONTABILIDADE E OS USUÁRIOS DA INFORMAÇÃO CONTÁBIL}

A Contabilidade é uma Ciência Social que se caracteriza pela fundamentação epistemológica, ou seja, baseia-se na investigação da natureza, fontes e validade do conhecimento. Seu principal objeto é o Patrimônio das Entidades, sendo que busca apreender e entender as mutações e variações sofridas pelo Patrimônio, sejam essas decorrentes da ação do homem ou efeitos da natureza.

O objetivo científico da Contabilidade, segundo a Resolução CFC n 774, de 16 de dezembro de 1994 , 
manifesta-se na correta apresentação do Patrimônio e na apreensão e análise das causas das suas mutações. Sob o ponto de vista pragmático, a Contabilidade visa prover os usuários com informações sobre aspectos da natureza econômica, financeira e física do Patrimônio da Entidade e suas mutações, englobando um vasto leque de registros e demonstrações.

O objetivo principal da Contabilidade, conforme a Estrutura Conceitual Básica da Contabilidade - Deliberação $C V M n^{\circ}$ 29, de 05 de fevereiro de 1986, é:

permitir, a cada grupo principal de usuários, a avaliação da situação econômica e financeira da entidade, num sentido estático, bem como fazer inferências sobre suas tendências futuras.

Nesse sentido, as demonstrações contábeis não devem, apenas, representar fatos passados e presentes de uma Entidade, mas serem instrumentos de predição e análise de tendências futuras. A Contabilidade, segundo a citada Deliberação, não deve configurar uma disciplina neutra e se restringir à busca de uma verdade ou beleza intrínseca, mas ser um instrumento útil para a tomada de decisões dos usuários.

O objetivo básico da Contabilidade, conforme ludícibus (2000, p. 23), reside no fornecimento de informações econômicas para os vários usuários, de modo a propiciar decisões racionais.

O modelo decisório de cada usuário, entretanto, possui detalhes que ainda não são suficientemente conhecidos e revela a necessidade de um "arquivobase" de informação contábil, com saídas periódicas, capaz de suprir o maior número possível de usuários. Segundo ludícibus (2000, p.19), é necessário:

construção de 'um arquivo básico de informação contábil' que possa ser utilizado, de forma flexível, por vários usuários, cada um com ênfases diferentes neste ou naquele tipo de informação, neste ou naquele princípio de avaliação, porém extraídos todos os informes do arquivo básico ou 'data base' estabelecido pela Contabilidade.

O objetivo essencial da divulgação financeira, segundo Hendriksen e Breda (1999, p. 107), é o fornecimento de informações que permitam que os investidores sejam capazes de predizer os fluxos futuros de caixa da empresa. A informação, para ser útil, deve ser relevante (oportuna, possuir valor preditivo e valor como feedback) e confiável (verificável, neutra e apresentar fidelidade de representação).

A Contabilidade, em suma, visa fornecer informações úteis a uma diversa gama de usuários, cada qual com necessidades e interesses específicos, de forma a orientá-los no processo de tomada de decisões econômicas, ou seja, na melhor escolha entre as diversas alternativas de uso de recursos disponíveis. Nesse contexto, deve identificar, mensurar, registrar e interpretar os fatos, traduzindo-os em informações úteis tanto para os usuários internos como externos.

\section{O CONCEITO DE LUCRO}

\subsection{A importância da Ciência Econômica no conceito de lucro}

No âmbito da sociedade capitalista, caracterizada pela propriedade privada de recursos econômicos, o lucro é a remuneração pelo uso do fator de produção Capacidade Empresarial, considerando-se a combinação dos demais fatores de produção (Terra, Capital e Trabalho). Cada fator recebe uma recompensa pela sua participação no processo de produção, sendo que as remunerações pelo uso da Terra, Capital e TrabaIho são, respectivamente, Renda de Terra, Juro e Salário. O lucro é, em suma, a recompensa e a motivação para a instalação e continuidade de um empreendimento na sociedade capitalista.

Na Ciência Econômica, há preocupação com os recursos limitados da economia, buscando-se a alocação ótima dos recursos escassos e das alternativas disponíveis para a maximização da utilidade e da riqueza dos agentes econômicos.

O conceito de lucro, nesse contexto, é um importante referencial para orientar as decisões econômicas dos agentes. $O$ conceito de lucro, no âmbito das atividades empresariais - caracterizadas pela busca da maximização da riqueza dos proprietários e dos stakeholders - é um importante indicador de sucesso das empresas.

Cabe à Ciência Contábil, por sua vez, a tarefa de quantificar os eventos econômicos de maneira lógica, objetiva e sistemática, ou seja, identificar, reconhecer, mensurar e registrar as transações em termos físicos e monetários, com informações voltadas aos usuários. 
O elemento lucro é importante tanto para a Ciência Econômica quanto para a Ciência Contábil que, apesar de enfoques diferentes, são áreas correlacionadas e, até certo ponto, complementares, à medida que há contribuições relevantes de ambas as ciências.

\subsection{As diferenças entre os conceitos de lucro contábil e lucro econômico}

A partir da década de 30, após o período da Grande Depressão, a Demonstração de Resultado tornou-se mais importante que o Balanço Patrimonial e a apuração do lucro líquido tornou-se o ponto central das demonstrações contábeis.

O conceito de lucro contábil possui raízes filosóficas nos conceitos econômicos de lucro, capital e manutenção do capital ou da riqueza.

Adam Smith, na obra The Wealth of Nations (1776), foi o primeiro a definir lucro como quantia a ser consumida sem prejudicar o capital, incluindo tanto o capital fixo quanto o capital circulante.

J. R. Hicks, na obra Value and Capital (1946), definiu lucro como "a quantia que uma pessoa pode consumir durante um período de tempo, estando essa pessoa tão bem no final do período como estava no início". Tanto para Smith quanto para Hicks, o lucro está relacionado com a manutenção da riqueza ou do capital do indivíduo.

Chang (1962, p. 639) define o lucro da empresa como "a quantia máxima que a firma pode distribuir como dividendos e ainda esperar estar tão bem no final do período como estava no começo."

Solomons (1961, p.373) adaptou o conceito de lucro proposto por Hicks para uma entidade de negócios, definindo-o como "a quantia pela qual seu patrimônio líquido aumentou durante o período, com os devidos ajustes sendo feitos para qualquer novo aporte de capital contribuído por seus donos ou para qualquer distribuição feita pela empresa para seus proprietários". O autor diferencia o lucro hicksiano do lucro contábil, ao asseverar que "o lucro hicksiano demanda que, na avaliação do patrimônio líquido, capitalizemos os recebimentos líquidos futuros esperados, enquanto que o lucro contábil requer somente que avaliemos os ativos com base em seus custos não expirados".
Nesse contexto, há três pontos fundamentais que devem ser destacados, a saber:

- o lucro econômico é apurado pelo incremento do patrimônio líquido;

- o patrimônio líquido é mensurado pela capitalização dos recebimentos líquidos futuros;

- o lucro contábil não guarda nenhuma relação com o lucro econômico, sendo os ativos avaliados tãosomente por seus custos não expirados.

A essência do conceito de lucro econômico reside, portanto, no incremento do patrimônio líquido, decorrente das operações da entidade ou da valorização de seus ativos. O lucro econômico, ao ser mensurado pelo incremento do patrimônio líquido, requer avaliação de todos os ativos da empresa com base nos recebimentos líquidos futuros esperados, com o cálculo do valor presente dos fluxos dos benefícios futuros.

Quando se utiliza o valor presente como representação dos valores dos atributos dos ativos, conforme Martins (2002, p.50), beneficia-se a identificação imediata dos maiores geradores de valor. O uso do valor presente líquido em uma entidade com um único ativo, por exemplo, implica na busca do valor econômico daquela entidade. Sob esse prisma, considera-se que o lucro econômico no período é a diferença entre o valor presente líquido dos fluxos futuros da entidade.

Hendriksen e Breda (1999, p.199) destacam algumas das críticas ao lucro contábil em sua forma tradicional:

- conceito de lucro contábil ainda não se encontra claramente formulado;

- não há base teórica permanente para o cálculo e apresentação do lucro contábil;

- as práticas contábeis geralmente aceitas permitem variações na mensuração do lucro do exercício de empresas diferentes;

- as variações do nível de preços têm modificado o significado do lucro medido em termos monetários históricos;

- outras informações podem ser mais úteis para investidores e acionistas, no que diz respeito à tomada de decisões de investimento.

A teoria e a prática contábil, conforme assevera Guerreiro (1989, p. 198), devem caminhar para um consenso em torno de um único conceito de lucro que esteja o mais próximo possível do conceito de lucro econômico.

No quadro a seguir, tem-se as principais diferenças entre Lucro Contábil e Lucro Econômico, a saber: 


\begin{tabular}{l|l}
\multicolumn{1}{c}{ LUCRO CONTÁBIL } & \multicolumn{1}{c}{ LUCRO ECONÔMICO } \\
Maior Objetividade. & Maior Subjetividade. \\
\hline $\begin{array}{l}\text { Apurado pelo confronto entre receitas realizadas pelas } \\
\text { vendas e custos consumidos (ativos expirados). }\end{array}$ & $\begin{array}{l}\text { Apurado pelo incremento no valor presente do } \\
\text { Patrimônio Líquido. }\end{array}$ \\
\hline Os ativos são avaliados na base de custos originais. & $\begin{array}{l}\text { Os ativos são avaliados pelo valor presente do fluxo } \\
\text { de benefícios futuros. }\end{array}$ \\
\hline O Patrimônio Líquido aumenta pelo lucro. & O lucro deriva do aumento do Patrimônio Líquido da entidade. \\
\hline Ênfase em Custos. & Énfase em Valores. \\
\hline Não reconhece ganhos não realizados. & Reconhecimento de ganhos realizados e não realizados. \\
\hline Não se efetuam ajustes em função de mudanças nos & $\begin{array}{l}\text { São efetuados ajustes devidos a mudanças nos níveis de } \\
\text { preços dos bens na economia. }\end{array}$ \\
níveis de preços dos bens na economia. & "Amarração" do lucro à condição de aumento da riqueza, \\
\hline "Amarração" do lucro à condição de distribuição de dividendos. & independentemente da condição de distribuição de dividendos. \\
\hline Não reconhecimento do "Goodwill". & Reconhecimento do "Goodwill". \\
\hline Utilização de regras e de critérios dogmáticos. & Utilização de regras e critérios econômicos.
\end{tabular}

Fonte: GUERREIRO, Reinaldo. Modelo Conceitual de Sistema de Informação de Gestão Econômica: Uma Contribuição à Teoria da Contabilidade. Tese de Doutoramento, FEA-USP, 1989, p. 196-197. Adaptado.

Do quadro comparativo, depreende-se que o lucro econômico, realmente, não guarda nenhuma relação com o lucro contábil. O lucro econômico é um conceito mais amplo e pressupõe maior subjetividade, à medida que envolve expectativas futuras, constituindo uma informação mais rica do que o lucro contábil, capaz de suprir, adequadamente, os modelos de decisão dos usuários da informação contábil.

Na literatura estrangeira, verifica-se distinção entre lucro contábil e lucro econômico, com a utilização do conceito de custo de oportunidade.

Segundo o dicionário AmosWeb Economic': Accounting profit is the difference between a business's revenue and its accounting expenses. This is the profit that's listed on a company's balance sheet, appears periodically in the financial sector of the newspaper, and is reported to the Internal Revenue Service for tax purposes. It frequently has little relationship to a company's economic profit because of the difference between accounting expense and the opportunity cost of production. Some accounting expense is not an opportunity cost and some opportunity cost it does not show up as an accounting expenses.

Segundo Mankiw (2001, p.270/272), o custo de oportunidade é o custo da renúncia no processo decisório, ao se optar por uma das alternativas. Conforme o autor, o lucro contábil considera apenas os custos explícitos, ou seja, aqueles que implicam pagamento em dinheiro. O lucro econômico, por sua vez, considera o custo de oportunidade, que engloba tanto os custos explícitos como os custos implícitos. O custo de oportunidade não é calculado, na maioria das vezes, pelas dificuldades quanto à mensuração, devido à subjetividade que lhe é inerente.

Para Stewart (2003, p.66), o lucro econômico corrige as distorções do lucro contábil, ao incorporar o custo de oportunidade. O caso Enron, ilustra o autor, mostra que a performance dessa grande corporação apenas considerava o lucro contábil, o que estava em conformidade com os USGAAP Generally Accepted Accounting Principles, mas em desacordo com os preceitos econômicos. Assim sendo, os números contábeis não refletiam a realidade econômica da empresa.

Frezatti (1999, p.01), ao tratar de ROI (Return on Investment), o indicador financeiro de longo prazo mais utilizado pelas empresas norte-americanas cobertas pela revista Fortune, cita que uma das limitações do indicador é desconsiderar o elemento risco, também ignorado pelo lucro contábil: "De maneira simplista, podemos distinguir o risco do negócio e risco financeiro. A figura do lucro contábil não incorpora nenhum desses tipos".

\footnotetext{
1 "http://www.amosweb.com/cgi-bin/gls.pl?fcd=dsp\&key=accounting+profit"

http://www.amosweb.com/cgi-bin/gls.pl?fcd=dsp\&key=accounting+profit, acesso em 10.07.2003.
} 


\section{AS CONVENÇÕES CONTÁBEIS E A ESTRUTURA CONTÁBIL TRADICIONAL}

Os Princípios Fundamentais da Contabilidade Entidade, Continuidade, Oportunidade, Registro pelo Valor Original, Atualização Monetária, Competência e Prudência - representam o cerne das doutrinas e teorias relativas à Ciência Contábil, conforme o entendimento científico e profissional predominante e buscam reunir e condensar os Postulados, Princípios e Convenções já existentes.

A estrutura conceitual da Contabilidade no Brasil, segundo ludícibus (2000, p. 46/75), está dividida em: Postulados (Entidade e Continuidade); Princípios (Custo original como base de valor; Realização da receita e da confrontação das despesas/Competência; Denominador comum monetário) e Convenções (Objetividade; Materialidade/Relevância; Conservadorismo e Uniformidade/Consistência).

A estrutura contábil tradicional encontra-se fundamentada pela Objetividade e pelos Princípios Contábeis Geralmente Aceitos, estando condicionada a necessidades pragmáticas, tais como: normas, convenções e consenso profissional. O lucro contábil tradicionalmente conhecido, apurado pelo confronto entre receita realizada e o custo consumido, é um dos reflexos dessa estrutura.

A objetividade é uma norma, convenção ou restrição que expressa, basicamente, informações lastreadas em fatos passados, de caráter histórico e verificável, fundamentadas em transações efetivamente ocorridas e em documentos comprobatórios, com mensurações caracterizadas pela impessoalidade e racionalidade. A mensuração do ativo, sob a ótica da Objetividade, considera basicamente o seu custo histórico.

Segundo Hendriksen (1971, p. 114/116), a objetividade pode apresentar significados distintos:

- mensurações impessoais;

- mensurações baseadas em consenso de experts qualificados;

- mensurações lastreadas em evidência verificável;

- valor da dispersão estatística das mensurações de um atributo, quando realizadas por vários pesquisadores.

Quanto às mensurações impessoais, tornase difícil separar completamente as crenças do mensurador em relação ao objeto de mensuração. As mensurações verificadas por consenso entre experts qualificados podem ser tidas como "objetivas", mas nem sempre os procedimentos e critérios adotados podem ser considerados objetivos sob uma ótica mais científica.Nas mensurações lastreadas em evidência verificável, a evidência (cujo critério de seleção pode ser objeto de viés pessoal) pode se sobrepor à mensuração propriamente dita. Quanto à dispersão estatística das mensurações de um atributo, pode-se considerar que a objetividade de uma mensuração pode ser avaliada pelo desvio-padrão em relação à média do atributo, mas o próprio valor da média pode não retratar, adequadamente, o atributo a ser mensurado.

As mensurações contábeis envolvem estimativas de valores e, portanto, quantificações monetárias com graus de incerteza. A convenção do Conservadorismo, que consiste na divulgação no menor valor possível para ativos/receitas e do maior valor possível para os passivos/despesas, busca traçar um cenário "mais pessimista do que otimista", de modo a reduzir os riscos.

A convenção da Materialidade relaciona-se com a noção de custo versus benefício da informação contábil gerada. Uma informação é material quando é relevante, sendo que sua omissão das demonstrações contábeis ou notas explicativas pode acarretar julgamento e decisões equivocadas a respeito de uma entidade, sua situação econômica-financeira, tendências e perspectivas. Nem sempre uma informação com alto grau de detalhamento e requinte gera benefícios superiores aos custos, em razão dos esforços humanos, recursos e tempo utilizados.

A convenção da Consistência refere-se à necessidade de adoção de critérios contábeis consistentes e uniformes ao longo do tempo, de modo a possibilitar a comparabilidade dos relatórios contábeis e a viabilidade dos estudos preditivos. Mudanças nos cenários ou uma reflexão sobre a melhor utilização de outro critério, entretanto, pode levar a Contabilidade a adotar novos critérios. A Consistência e a Materialidade viajam juntas, conforme FIPECAFI (2000, p.63), sendo que qualquer mudança de procedimento (se material) deve ser claramente evidenciada em notas explicativas. Os efeitos da mudança de critério contábil sobre o balanço e o resultado devem ser mensurados e bem enunciados. 
O custo histórico possui como um dos pilares a convenção do conservadorismo. O custo histórico, segundo ludícibus e Carvalho (2001, p.05), pode ser adequado apenas no momento do registro da transação, mas perde relevância no transcorrer do tempo, seja devido à inflação ou a outros fatores, tais como: inovações tecnológicas, obsolescência, alterações no processo produtivo, condições de mercado e ao impairment do ativo.

Conforme ressaltam Hendriksen e Breda (1999, p.93), a principal dificuldade na ênfase no processo de contabilização e na estrutura convencional de divulgação é que certos termos contábeis, tais como lucro líquido e receita, e mensurações como custo histórico, possuem pouco ou nenhum significado interpretacional no mundo real.

Houve, nas últimas décadas, grandes mudanças econômicas, políticas e sociais, assim como inovações no campo tecnológico e em diversas áreas do conhecimento científico.

A atual realidade econômica, conforme lembra Silva (2000, p.72), é caracterizada por novos desafios, tais como: 1) competitividade global acirrada em função da gradual eliminação das barreiras comerciais; 2) intenso fluxo financeiro; 3) advento de novas formas de produção; 4) expansão das linhas de produtos; 5) diminuição dos ciclos de vida dos produtos; 6) rápido avanço científico e tecnológico; 7) novas relações trabalhistas e 8 ) grandes avanços na tecnologia da informação.

Nesse contexto, houve, sobretudo, mudanças das necessidades e exigências do mercado e de seus agentes econômicos. $\mathrm{O}$ investidor atual, importante usuário da informação, assim como a grande maioria dos usuários, não está mais interessado em valores passados, mas em informações contábeis com caráter preditivo e que proporcionem análise de tendências futuras.

Como ressalta Catelli (2001, p.86):

o investidor não está preocupado com custos, mas sim com valores, não está interessado prioritariamente no confronto entre receitas realizadas com custos expirados, mas sim com o incremento em sua parcela de riqueza alocada nessa entidade, não está preocupado com quanto foi seu investimento, mas sim quanto vale seu capital.

A curva de conhecimento da Contabilidade (17751975), elaborada por Leo Herbert August (1971) e apresentada por Most (1977, p.05), mostra um forte crescimento exponencial da Contabilidade, mormente a partir de 1950, com grande influência multidisciplinar (Economia, Administração, Psicologia, entre outras), a partir da década de 60.

A Contabilidade, entretanto, não se adaptou, integralmente, às transformações ocorridas na sociedade como um todo, sendo necessário repensar alguns conceitos e técnicas utilizados, tal como o princípio do custo como base de valor, por não atenderem mais às necessidades e exigências dos usuários ante a nova realidade econômica.

\section{A QUESTÃO DA MENSURAÇÃO DO ATIVO}

O lucro econômico, ao ser mensurado pelo incremento do patrimônio líquido, requer avaliação de todos os ativos da empresa com base nos recebimentos líquidos futuros esperados. O problema da mensuração do lucro, conforme Solomons (1961, p. 373), está intimamente relacionado com a avaliação do ativo.

A mensuração do ativo, sob a ótica da objetividade, prioriza o custo histórico (custo de aquisição). Sob a luz da subjetividade, busca-se a melhor expressão do valor num determinado contexto. No caso de uma máquina produtiva, por exemplo, o seu valor se traduziria no seu fluxo de benefícios futuros.

A característica essencial do ativo está na potencialidade de geração de benefícios futuros. A medida de valor de um ativo, conforme o Comitê de Conceitos Contábeis da American Accounting Association (1957) é "a soma dos preços futuros de mercado dos fluxos de serviços a serem obtidos, descontados pela probabilidade de ocorrência e pelo fator juro, a seus valores atuais".

No processo de mensuração dos ativos e no contexto de determinação do lucro econômico, Catelli e Guerreiro (2001, p.91/93) observaram os seguintes princípios básicos:

- o valor de um ativo é único e deve expressar o quanto ele vale para a empresa, em determinado momento. $O$ valor do ativo é o seu potencial de serviços e benefícios futuros, representando, sob o ponto de vista econômico, o montante de riqueza a ser gerado para a empresa. Tornase, pois, irrelevante se a avaliação do ativo deve 
ser efetuada com base em valores de entrada ou saída;

- o valor do ativo não deve ser influenciado pelas condições de pagamento, pois o potencial de serviços do ativo independe da forma como é financiado e deve ser analisado à luz da sua função dentro da empresa, na continuidade de suas operações;

- os custos históricos não expressam o valor do ativo para a empresa. Os custos históricos, mesmo quando atualizados, representam, no máximo, o valor do desembolso numa data passada, não representando o valor econômico do ativo;

- a mensuração do ativo deve estar de acordo com o postulado da continuidade da entidade, pressuposto básico do empreendimento empresarial;

- a depreciação dos ativos corresponde à perda do potencial de geração de benefícios;

- o valor de um ativo pode variar de uma empresa para outra, de acordo com a sua finalidade;

- o mercado é o validador do potencial de serviços dos ativos. As oscilações do mercado afetam os preços projetados para os produtos/serviços futuros e, conseqüentemente, o resultado econômico e a riqueza da empresa. Portanto, os ganhos e perdas decorrentes da valorização/desvalorização de ativos devem ser reconhecidos, mesmo que não realizados;

- o conceito de realização da receita pela venda para efeito de determinação do lucro não é relevante;

- o valor do goodwill da empresa deve ser reconhecido.

O reconhecimento do goodwill criado pela empresa, apesar de sua relevância, não é enfatizado pela Contabilidade. Na metodologia proposta por Martins (1972, p.59), o valor do goodwill corresponde, basicamente, à diferença entre o valor presente dos fluxos dos benefícios futuros produzidos pela empresa - valor econômico global da empresa - e o valor da soma dos valores econômicos individuais dos ativos da empresa.

O goodwill envolve elementos subjetivos, mas que constituem esforços diferenciados que podem interferir na competitividade e continuidade de uma empresa, tais como: localização geográfica, pesquisa e desenvolvimento, bons relacionamentos com clientes e fornecedores, treinamento de funcionários, entre outros. Conforme ludícibus (2001, p. 211), se tais esforços diferenciados não forem evidenciados, haverá o fornecimento de um quadro "injusto", enviesado e não neutro para os usuários.

Os ativos devem ser avaliados de modo que o patrimônio líquido da empresa reflita efetivamente o quanto vale a empresa num determinado momento. Para isso, o patrimônio líquido da empresa deve representar o seu custo de oportunidade, ou seja, o quanto os proprietários deixarão de ganhar em uma decisão alternativa à continuidade da empresa.

\section{O CONCEITO DO FAIR VALUE}

O conceito de fair value - valor justo - é de grande relevância no atual contexto da Contabilidade e das normas e práticas contábeis internacionais.

O custo histórico, amplamente adotado e considerado um dos sólidos pilares da Contabilidade durante anos, tem como principais vantagens a objetividade e a simplicidade na contabilização. O critério do custo histórico, conforme PIRES e RODRIGUES², não se ajusta aos elementos geradores de valor da nova economia e a necessidade de combinação de critérios fez com que "o custo histórico começasse a ser substituído pelo fair value".

O fair value, segundo Hendriksen e Breda (1999, p. 309), é o valor total sobre o qual os investidores têm direito a um retorno justo. O termo "justo" ou "adequado", conforme se deve destacar, envolve subjetividade e se pressupõe mais amplo que o conceito do custo histórico.

O FASB (Financial Accounting Standards Board), através do pronunciamento SFAS 142 - Goodwill and Other Intangible Assets, considerou o fair value de um ativo (passivo) como o montante pelo qual o ativo (passivo) poderia ser comprado (incorrido) ou vendido (liquidado) em uma transação corrente entre partes dispostas, ou seja, numa situação em que não haja venda forçada ou liquidação.

As cotações de mercado, se disponíveis, configuram, em princípio, a melhor evidência de fair value e devem ser utilizadas como base de mensuração.

${ }^{2}$ PIRES, Amélia M. RODRIGUES, Fernando P. Um novo paradigma valorimétrico: o declínio do custo histórico. 
Quando as cotações de mercado não estão disponíveis, a estimativa do fair value deve ser baseada na melhor informação disponível, incluindo cotações de ativos/passivos semelhantes e resultados de outras técnicas de avaliação, como o valor presente.

O FASB emitiu normativos visando ao reconhecimento, à mensuração e à evidenciação dos instrumentos financeiros, com ênfase para os derivativos. Os instrumentos derivativos, conforme o SFAS 133 - Accounting for Derivative Instruments and Hedging Activities, apresentam as seguintes características contratuais: existência de um ativo-base, investimento inicial inexistente ou muito pequeno e liquidação da operação em uma data futura.

$\mathrm{Na}$ literatura internacional, há casos de grandes prejuízos em operações com derivativos protagonizados por empresas de diversos setores, tais como: Daiwa Securities Metallgesechaift, Orange Country, Procter \& Gamble, assim como a falência do Banco Barings. Com o SFAS 107 - Disclosure about fair value of Financial Instruments (1991), houve a inclusão de operações anteriormente off balance sheet nas demonstrações contábeis, visando à maior transparência das transações.

A subjetividade é inerente a operações com derivativos e, conforme destaca a FIPECAFI (2000, p. 488 ), utilizar uma medida objetiva como custo histórico para os instrumentos derivativos é "assumir deliberadamente a postura de fornecer uma informação não relevante para o usuário".

O IASB (International Accounting Standards $B o a r d)$, por sua vez, emitiu pronunciamentos que tratam o fair value como medida de valor: o IAS 33 (Financial Instruments Disclosure and Presentation, 1995) e o IAS 39 (Financial Instruments: Recognition and Measurement, 1998). Para o IASB, o fair value é "o valor pelo qual um ativo pode ser transacionado, ou um passivo liquidado, entre partes conhecedoras, dispostas a negociar em uma transação entre partes não relacionadas".

Sob essa ótica, o mercado deve ser eficiente, ou seja, tanto o comprador como o vendedor devem conhecer a cotação do ativo/passivo e estar dispostos a realizar a compra/venda, sem que haja informação privilegiada ou favorecimento para qualquer uma das partes.

Os normativos do Banco Central do Brasil, embora ainda não tratem do fair value, vêm seguindo a evolução dos normativos internacionais, estabelecendo o ajuste a valor de mercado para os títulos e valores mobiliários e os instrumentos derivativos, conforme a Circular 3.068, de 08.11.2001 e a Circular 3.082, de 30.01.2002.

Segundo a Circular 3.068/2001, os títulos e valores mobiliários adquiridos por instituições financeiras, exceto cooperativas de crédito, agências de fomento e sociedades de crédito ao microempreendor, devem ser registrados pelo valor efetivamente pago, inclusive corretagens e emolumentos, e classificados nas seguintes categorias:

I. Títulos para negociação (trading);

II. Títulos disponíveis para venda (available-for-sale);

III. Títulos mantidos até o vencimento (held-tomaturity).

$\mathrm{Na}$ categoria I, devem ser registrados os títulos e valores mobiliários adquiridos com o objetivo de negociação ativa e freqüente. Na categoria III, devem ser registrados os títulos e valores mobiliários, exceto ações não resgatáveis, com intenção e capacidade financeira da instituição de mantê-los em carteira até o vencimento. Na categoria II, devem ser registrados os títulos e valores mobiliários que não se enquadrem nas categorias I e III.

Os títulos e valores mobiliários classificados nas categorias I e II devem ser ajustados pelo valor de mercado, no mínimo por ocasião dos balancetes e balanços, computando-se a valorização ou desvalorização em contrapartida:

I. À adequada conta de receita ou despesa, no resultado do período, quando relativa a títulos e valores mobiliários classificados na categoria títulos para negociação;

II. À conta destacada do patrimônio líquido, quando relativa a títulos e valores mobiliários classificados na categoria títulos disponíveis para venda, pelo valor líquido dos efeitos tributários.

Para a apuração de valor de mercado podem ser utilizados como parâmetro:

I. O preço médio de negociação no dia da apuração ou, quando não disponível, o preço médio de negociação no dia útil anterior;

II. O valor líquido provável de realização obtido mediante adoção de técnica ou modelo de precificação;

III. O preço de instrumento financeiro semelhante, levando em consideração, no mínimo, os 
prazos de pagamento e vencimento, o risco de crédito e a moeda ou indexador.

$\mathrm{Na}$ Circular 3.082/2002, que trata do registro e avaliação contábil dos instrumentos financeiros derivativos, as operações com derivativos devem ser avaliadas pelo valor de mercado, no mínimo por ocasião dos balancetes mensais e balanços, computando-se a valorização ou desvalorização em contrapartida à adequada conta de receita ou de despesa, no resultado do período.

O lucro contábil, ao priorizar o custo histórico, não se adequa às necessidades e novas exigências da atualidade, indo contra os preceitos que fundamentam o fair value.

\section{ESTUDO EXPLORATÓRIO E ANÁLISE DE RESULTADOS}

O estudo exploratório buscou constatar, de forma geral, o grau de assimilação, utilização e divulgação do conceito de lucro econômico pelos profissionais da área contábil.

A pesquisa, com a utilização de questionário, foi realizada junto a profissionais cujas atividades estão diretamente relacionadas com a contabilidade, na área de auditoria. O grupo selecionado é composto por pessoas que possuem, no mínimo, nível superior e são reconhecidas no mercado como profissionais de boa formação e conhecimento em contabilidade.

O questionário foi encaminhado, através de $e$ mail, a 247 pessoas, com resposta de 49 , correspondendo a $19,83 \%$ do total.

Dada a natureza do trabalho, não há pretensão de fazer generalizações ou chegar a conclusões finais.

1․ Questão: Visa verificar se o conceito de lucro considerado adequado pelos profissionais, aproximase mais do conceito de lucro contábil ou de lucro econômico.

1) Qual é melhor definição de lucro? (escolher apenas 01 alternativa)

(a) Lucro é o resultado positivo do confronto entre receita realizada e custo consumido.

(b) Lucro é a quantia máxima que a empresa pode distribuir como dividendos e ainda continuar tão bem ao final do período como no início. (c) Lucro é o apurado pelo incremento no valor presente do patrimônio líquido.

(d) Lucro é o mensurado segundo os princípios contábeis geralmente aceitos, considerando-se o custo como base de valor e o princípio da realização da receita.

(e) Lucro é o fluxo de riqueza ou serviços em excesso àquele necessário para manter o capital constante.

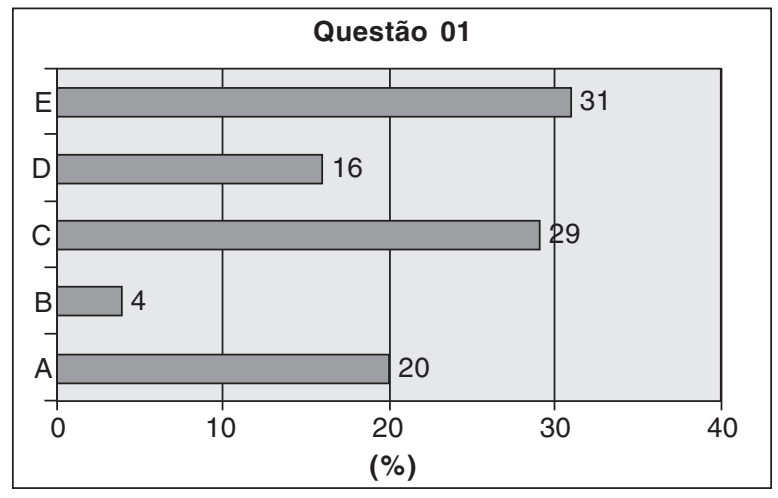

As alternativas $A$ e $D$ contêm o conceito do lucro contábil tradicional e a alternativas $\mathrm{B}, \mathrm{C}$ e E correspondem ao lucro em termos econômicos.

As alternativas mais votadas foram as relacionadas ao lucro econômico, sendo que 31\% têm a visão de lucro como o excedente necessário para manter o capital constante e $29 \%$ "visualizaram", realmente, a essência do lucro econômico, que é o incremento no valor presente do patrimônio líquido.

Cabe observar que $36 \%$ da amostra (total dos que optaram pelas alternativas $A$ ou D) ainda consideram como melhor definição de lucro aquela que corresponde ao lucro contábil tradicional, ou seja, o resíduo do confronto entre receita realizada e custo incorrido.

$2^{\text {a }}$ questão: Visa avaliar a visão do conceito de lucro econômico dos profissionais da área contábil.

2) Para você, o conceito de lucro econômico é:

(a) um conceito novo no estudo da Contabilidade.

(b) um conceito que tem o mesmo significado que o lucro contábil.

(c) um conceito que não guarda nenhuma relação com o lucro contábil.

(d) um conceito subjetivo, aplicável apenas no contexto da ciência econômica. 


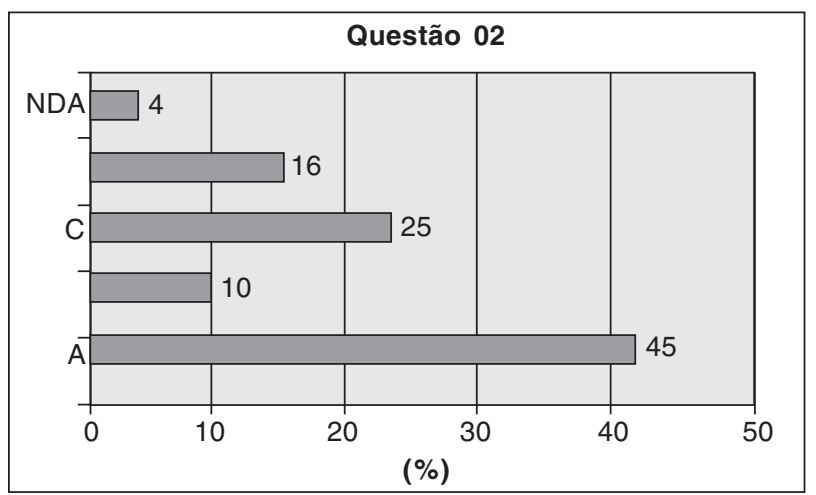

Nessa segunda questão, apenas 01 pessoa optou por 02 alternativas simultaneamente (no caso, alternativas $\mathrm{C}$ e D) e $4 \%$ responderam nda (nenhuma das anteriores), que não constava dentre as alternativas.

Verifica-se que a alternativa A (o conceito de lucro econômico é novo no estudo da Contabilidade) representou uma escolha expressiva da amostra (45\%), ao passo que apenas $25 \%$ optaram pela alternativa $\mathrm{C}$ (um conceito que não guarda nenhuma relação com o lucro contábil).

Para $16 \%$, o conceito de lucro econômico possui aplicabilidade apenas na Ciência Econômica.

Ante esse resultado, entende-se que o conceito de lucro econômico ainda não se encontra claramente definido e difundido entre os profissionais da área contábil, sendo visto como "algo inédito" no estudo da Contabilidade.

$3^{\text {a }}$ questão: Objetiva verificar se os profissionais da área contábil consideram as premissas fundamentais na mensuração do resultado econômico.

3) Na busca da mensuração do lucro certo, 0 valor do ativo a ser considerado (escolher 01 ou mais alternativas):

(a) é o valor presente do fluxo de benefícios futuros.

(b) é o valor de aquisição (custo histórico).

(c) é o potencial de geração de serviços.

(d) é o custo histórico corrigido pela variação do poder aquisitivo da moeda.

(e) depende das condições de pagamento, ou seja, se foi adquirida à vista ou com capital de terceiros.

(f) é influenciado pelas oscilações do mercado.

(g) pode variar, de acordo com a finalidade da empresa.

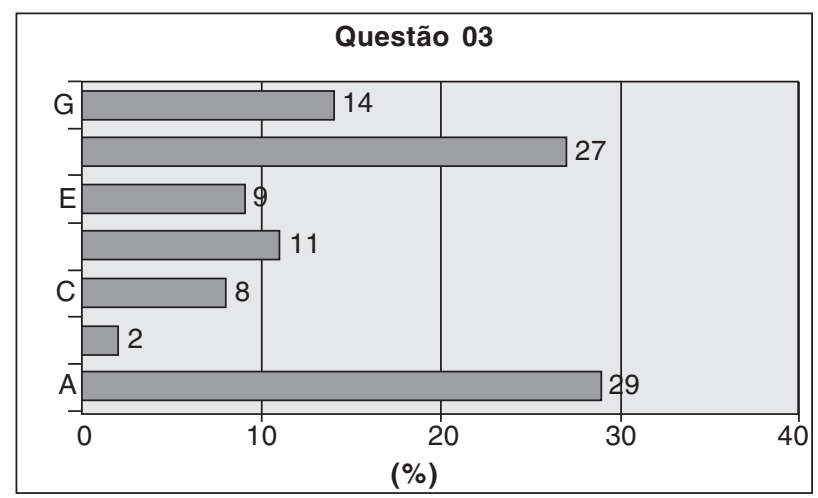

Para os participantes da pesquisa, o valor do ativo a ser considerado na mensuração do lucro certo é o valor presente dos benefícios futuros (29\%), sendo que é influenciado pelas oscilações do mercado (27\%). Observa-se que o custo histórico teve uma votação inexpressiva (2\%) e o custo histórico corrigido correspondeu a $11 \%$ do total. O resultado mostra que o princípio do custo histórico como base de valor já é considerado de pouca relevância junto aos profissionais da área contábil.

A alternativa errada (o ativo depende das suas condições de pagamento) correspondeu a $9 \%$ do total.

É importante notar que a potencialidade de geração de serviços do ativo, uma das características essenciais do ativo, correspondeu a apenas $8 \%$ do total.

$4^{a}$ questão: Objetiva verificar que o grau de aceitação do lucro contábil pelos profissionais da área contábil.

4) Com relação à afirmativa: "O lucro contábil é uma informação rica e adequada para a tomada de decisões econômicas, você:

(a) Concorda plenamente.

(b) Concorda simplesmente.

(c) Concorda ou discorda parcialmente.

(d) Discorda simplesmente.

(e) Discorda totalmente.

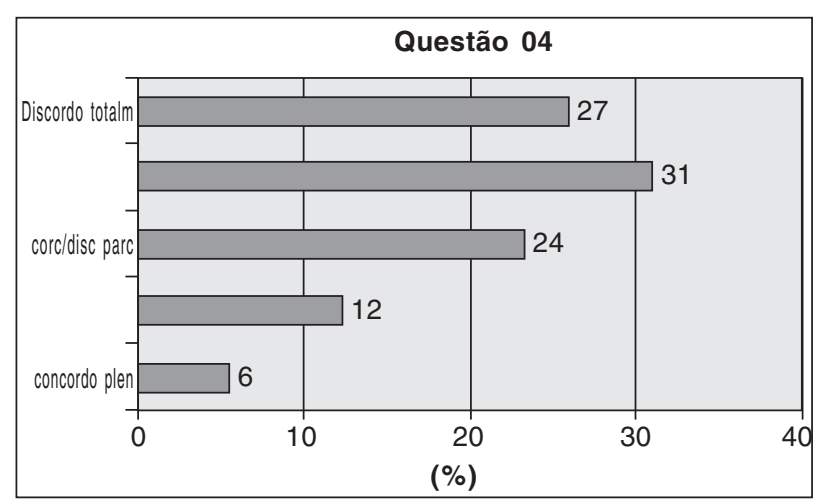


A pergunta utiliza escalas de atitudes e, por isso, considera-se a média das freqüências relativas ponderadas. A resposta Concordo Plenamente foi escoIhida como unidade de apresentação máxima do evento, com ponderação 2. As outras categorias, por conseguinte, apresentaram as seguintes ponderações: Concordo Simplesmente (1), Concordo ou Discordo Parcialmente (0), Discordo Simplesmente (-1) e Discordo Totalmente (-2).

O resultado do cálculo da freqüência relativa ponderada foi de $-0,61$, mostrando que os participantes tendem a discordar que o lucro contábil seja uma informação rica e adequada para a tomada de decisões econômicas. Nota-se que apenas $6 \%$ concordam plenamente com a afirmativa.

$5^{a}$ questão: Visa verificar o grau de utilização do conceito de lucro econômico.

5) $\mathrm{Na}$ análise das demonstrações contábeis, você utiliza o conceito de lucro econômico:

(a) Sempre.

(b) Freqüentemente.

(c) Às vezes.

(d) Raramente.

(e) Nunca.

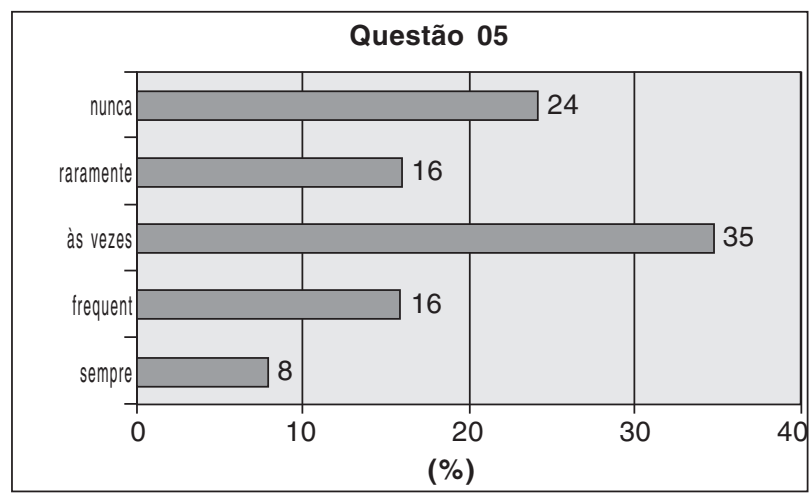

Consideram-se as escalas de atitudes, sendo que as categorias apresentaram as seguintes ponderações: Sempre (2), Freqüentemente (1), Às vezes (0), Raramente (-1) e Nunca (-2). O resultado da freqüência relativa ponderada foi de $-0,32$, mostrando que o conceito de lucro econômico tende a ser muito pouco utilizado na análise das demonstrações financeiras.

A alternativa mais votada foi Às vezes (35\%), sendo que apenas $24 \%$ dos participantes (total dos que optaram pelas alternativas Sempre e Freqüentemente) mostram regularidade no uso do conceito de lucro econômico. Cabe observar que $24 \%$ da amostra nunca utilizam o conceito de lucro econômico. A hipótese do artigo é verificada, ou seja, a pesquisa mostra indícios de que não há pleno uso do conceito de lucro econômico pelos profissionais de Contabilidade.

\section{CONSIDERAÇÕES FINAIS}

A Contabilidade, em sua estrutura tradicional, encontra-se alicerçada pelo conservadorismo, convenção da Objetividade e Princípios Contábeis Geralmente Aceitos.

O lucro contábil, apurado pelo confronto entre receita realizada e custo incorrido, está em consonância com os preceitos antigos, volta-se basicamente para o usuário externo e não reflete a realidade patrimonial, econômica e financeira das entidades.

O lucro econômico, apurado pelo incremento no valor presente do patrimônio líquido, atende tanto ao usuário externo como ao interno, constituindo instrumental rico e adequado para a tomada de decisões econômicas.

No estudo exploratório, baseado em pesquisa realizada junto a profissionais da área contábil atuantes no mercado, verificou-se que o lucro econômico, apesar de sua relevância, não se encontra plenamente difundido e utilizado, de forma que "a cultura do lucro contábil" ainda permanece no âmbito da Contabilidade Aplicada.

Constatou-se que a maioria dos participantes da pesquisa consideram como definições de lucro adequadas aquelas que correspondem ao lucro econômico, sendo que o conceito ainda é visto como algo novo no estudo da Contabilidade. A maioria dos participantes $(58 \%)$ discorda que o lucro contábil seja a ferramenta adequada para a tomada de decisões econômicas, mas apenas $24 \%$ utilizam o conceito de lucro econômico com regularidade.

Um aspecto positivo constatado na pesquisa é que o custo histórico, privilegiado na mensuração do ativo sob a ótica da Objetividade, é considerado pouco relevante (2\%), ao passo que benefícios futuros, característica essencial do ativo, teve $29 \%$ de representatividade.

Faz-se necessário que sejam repensados alguns conceitos tradicionalmente utilizados pela Contabilidade, tais como o custo histórico como base de valor e a realização da receita pela venda, assim como seja aprofundada a divulgação do conceito de lucro econômico, principalmente entre os profissionais da área Contábil atuantes no mercado, em face das novas exigências e desafios do contexto atual. 
BANCO CENTRAL DO BRASIL. Circular 3068 de 08.01.2001. . Circular 3082 de 30.01.2002.

BRASIL. Resolução CFC n 774, de 16 de dezembro de 1994. Aprova o apêndice à resolução sobre os princípios fundamentais da contabilidade.

CHANG, Emily Chen. Business income in accounting and economics. The Accouting Review, Oct, 1962.

CATELLI, Armando. Controladoria - Uma abordagem da Gestão Econômica GECON. $2^{a}$ ed. São Paulo: Atlas, 2001.

CATELLI, Armando, GUERREIRO, Reinaldo. Mensuração do Resultado Econômico, Caderno de Estudos FIPECAFI. São Paulo, set/1991.

COMISSÃO DE VALORES MOBILIÁRIOS. Deliberação CVM n 29, de 05.02.1986, que trata da Estrutura Conceitual Básica da Contabilidade.

COMISSÃO DE VALORES MOBILIÁRIOS. OFÍCIO-CIRCULAR/ CVM/SNC/SEP/No 02, de 22.06.1996, que trata da Contabilização do Imposto de Renda em face das Alterações produzidas pela Lei $n^{\circ}$ 9.249/95.

FIPECAFI. Manual de Contabilidade das Sociedades por Ações (aplicável às demais sociedades). São Paulo: Editora Atlas, 2000.

FREZATTI, Fábio. A implantação do ROI (Return on Investment) - um Case, out/1999.

GOULART, André Moura Cintra. O Conceito de Ativos na Contabilidade: um Fundamento a ser explorado. Revista Contabilidade \& Finanças - USP, São Paulo, jan/abr 2002.

GUERREIRO, Reinaldo. Modelo Conceitual de Sistema de Informação de Gestão Econômica: Uma Contribuição à Teoria da Comunicação da Contabilidade. 1989. Tese (Doutorado em Controladoria e Contabilidade) - Faculdade de Economia, Administração e Contabilidade. Universidade de São Paulo, São Paulo.

GUERREIRO, Reinaldo, REIS, Ernando Antonio. O Papel da Subjetividade no Contexto da Contabilidade Gerencial. Congresso Brasileiro de Custos, 1998.

HENDRIKSEN, Eldon S. Accounting theory. Homewood: Richard D. Irwin, 1971.

, VAN BREDA, Michael F. Teoria da Contabilidade. São Paulo: Atlas, 1999.
INTERNATIONAL ACCOUNTING STANDARD BOARD. IAS 39: Financial instruments: recognition and measurement, 1998 (revisado em 2000).

IAS 32: Financial instruments: disclosure and presentation, 1995 (revisado em 1998).

IUDíCIBUS, Sérgio de. Teoria da Contabilidade. $6^{\mathrm{a}}$ ed. São Paulo: Atlas, 2000.

Lucro Contábil: Crepúsculo ou Ressurgimento? Caderno de Estudos FIPECAFI, São Paulo, n 1, outubro/1989.

, Conceitos econômico e contábil de lucro: simetrias e arritmias. Revista Brasileira de Contabilidade, v.24, n.96, nov/dez 95.

CARVALHO L. Nelson. Porque devemos ousar em Contabilidade. Boletim do Ibracon, maio de 2001.

MANKIW, Gregory. Principles of Economics. $2^{\text {nd }}$ Ed., Fort Worth: Harcourt College Publishers, 2001.

MARTINS, Eliseu. Contribuição à Avaliação do Ativo Intangível. 1972. Tese (Doutorado em Controladoria e Contabilidade), Faculdade de Economia, Administração e Contabilidade da Universidade de São Paulo, São Paulo.

MARTINS, Vinícius Aversari. Contribuição à avaliação do goodwill: depósitos estáveis, um ativo intangível. São Paulo, 2002. Dissertação (Mestrado em Controladoria e Contabilidade), Faculdade de Economia, Administração e Contabilidade da Universidade de São Paulo, São Paulo.

MOST, Kenneth. Accounting Theory. Ohio: 1977, Grid, Inc. PIRES, Amélia M. RODRIGUES, Fernando P. Um novo paradigma valorimétrico: o declínio do custo histórico.<http:// www.oroc.pt/rev17/page43.pdf>. Acesso em 10.09.04.

PONTE, Vera. Uma mensuração de lucro centrada em evidenciar o acréscimo de valor no ativo líquido. Caderno de Estudos, FIPECAFI, São Paulo, v.10, n. 17, 1998.

SILVA, Alexandre dos Santos. Análise das formas de reconhecimento da receita na Contabilidade: um enfoque no conceito econômico de lucro. 2000. Dissertação (Mestrado em Controladoria e Contabilidade) - Faculdade de Economia, Administração e Contabilidade. Universidade de São Paulo, São Paulo.

SOLOMONS, David. Economic and accounting concepts of income. The Accounting Review, Jan.1971.

STEWART, G. Bennett. How to fix accounting -measure and report economic profit. Journal of Applied Corporate Finance, v. 15, n 3, Spring 2003.

NOTA:

Endereço da autora:

Av. Paulista, 1804 - Cerqueira Cesar

São Paulo - SP

01310-922 